Conclusions In the present study, a high prevalence of UI symptoms was found in soccer athletes, with moderate reliability between the pad test and the ICIQ-SF; mild UI was found in both groups. The athletes had the highest scores on the General Health, Emotions and Sleep/Energy domains, which are considered to have the highest impact on quality of life.

\section{LIFE QUALITY IN WORKERS WITH RELATED MUSCULOSKELETAL DISORDERS}

${ }^{1}$ Andressa Soares, ${ }^{1}$ Fernanda Caetano, ${ }^{1}$ Joyce Braga, ${ }^{2}$ Antonio Fernandes, ${ }^{1,2}$ Eduardo Filoni. ${ }^{1}$ Cruzeiro Do Sul University, São Paulo, São Paulo, Brazil; ${ }^{2}$ University of Mogi Das Cruzes, Mogi Das Cruzes, São Paulo, Brazil

\subsection{6/oemed-2014-102362.185}

Objectives Analyse the quality of life of workers of administrative department who carry out repetitive functions in a medical certification central.

Method This study was carried out in a transversal analytical approaching. The sample was constituted by 62 workers of the administrative sector of a medical certification central in the state of São Paulo. As an instrument of gathering the data the used questionnaires were: Anamnesis Questionnaire with personal and professional data, Nordic Questionnaire, Job stress scale, SF-36 Quality of Life Questionnaire. The characterisation of the sample was obtained through descriptive statistics, where test $t$ and correlation of Pearson test were applied.

Results a According to the results of the analysis of the Nordic questionnaire, 33, 87\% mentioned feeling pain in the wrists and hands. In the correlation made among the data of SF-36 and Nordic questionnaire, it was showed that they presented complaints about the Nordic, minor was the score in the variables of SF-36: limitation by physical aspects, pain, vitality, emotional aspects and mental health.

Conclusions It is concluded that the most affected segments were wrists and hands, with 33, 87\%, followed by anklebone and feet with $16,13 \%$.

\section{COMPARATIVE STUDY ABOUT QUALITY OF LIFE BETWEEN WOMEN PRACTICING DANCE AND SEDENTARY WOMEN}

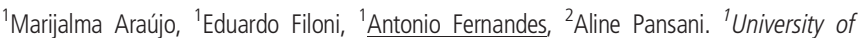
Mogi Das Cruzes, Mogi Das Cruzes, São Paulo, Brazili; ${ }^{2}$ Federal University of São Paulo, São Paulo, São Paulo, Brazil

\subsection{6/oemed-2014-102362.186}

Objectives This study aimed to compare Quality of life (QOL) of women who practice Jazz compared to sedentary women, in the Sports Centre-414 SESI in Sao Paulo - SP

Method We carried out a cross-sectional study, with women between 50 and 85 years old, divided into two groups: Activity Group (GA, n = 14) and Sedentary Group (GS, n = 14). QOL was analysed by the SF-36.

Results The GA had a significant improve in 6 domains of SF36 compared to GS $(\mathrm{p}<0.05)$.

Conclusions The results of this study suggest an improvement in the QOL of practitioners of jazz, especially in the physical and emotional aspects, compared to sedentary women.

\section{EFFECTS OF CHRONIC LOW-DOSE EXPOSURE TO IONISING RADIATION ON PHYSICIAN MICRO-VASCULAR STRUCTURE REVEALED BY NAIL FOLD CAPILLAROSCOPY}

${ }^{1}$ Pascal Wild, ${ }^{2}$ Christine Gauron, ${ }^{3}$ Christian Derock, ${ }^{3}$ Karine Champion, ${ }^{3}$ Pascal Cohen, ${ }^{4}$ Caroline Menez, ${ }^{5}$ Anne-Sophie Tellart, ${ }^{6}$ Hélène Thiel, ${ }^{1}$ Michel Grzebyk, ${ }^{7}$ Laurent Donadille, ${ }^{8}$ Raffaele Pennarola, ${ }^{9}$ Dominique Choudat. ${ }^{1}$ INRS, Vandoeuvre, France; ${ }^{2}$ INRS, Paris, France; ${ }^{3}$ APHP, Paris, France; ${ }^{4}$ University Hospital, Grenoble, France; ${ }^{5}$ University Hospital, Lille, France; ${ }^{6}$ University Hospital, Clermont-Ferrrand, France; ${ }^{7}$ IRSN, Fontenay Aux Roses, France; ${ }^{8}$ Naples University, Naples, Italy; ${ }^{9}$ University Paris Descartes, Paris, France

\subsection{6/oemed-2014-102362.187}

Objectives The aim of this study was to assess the long term pre-clinical effects of low-dose radiation on the micro-vascular structure among interventional physicians whose hands are exposed to ionising radiation in their daily practice.

Method The study, approved by the ethics committee, included 186 radiation-exposed (surgeons, cardiologists and radiologists) and 35 unexposed physicians. The study participants filled in a questionnaire describing their present and past daily practice from which the present and cumulative radiation exposures were estimated. Their dermal microcirculation was assessed by capillaroscopy of the nailfold of 8 fingers -thumbs excluded- of each study participant. Two quantitative scores characterising respectively extravasation and morphological abnormalities were obtained based on post-hoc codings of seven semi-quantitative indices by five capillaroscopists. These assessments were randomised and were blind to the exposure. The effect of the radiation exposure on both features was modelled using multilevel proportional odds regression adjusted for potential confounders. Results The exposure intensity of each act was greatest among surgeons but with a lesser number of acts. The mean estimated cumulated exposure was largest among radiologist and cardiologists.

No effect of the exposure could be detected on the extravasation score. The morphological anomaly score increased significantly with duration of exposure and cumulative exposure indices among surgeons and interventional radiologists contrary to cardiologists among which no effect could be detected.

Conclusions Capillaroscopy showed significant effects of chronic low-dose exposure to ionising radiation on micro-vascular structure among exposed physicians but its interest for individual monitoring has not been demonstrated.

\section{ASSESSMENT AND ESTIMATES OF EXPOSURE TO SYNTHETIC AMORPHOUS SILICA AT FIVE GERMAN PRODUCTION PLANTS}

${ }^{1,2}$ Peter Morfeld, ${ }^{3}$ Dirk Taeger, ${ }^{4}$ Heike Mitura, ${ }^{5}$ Axel Bosch, ${ }^{6}$ Adrian Nordone, ${ }^{7}$ Reinhard Vormberg, ${ }^{8}$ Robert McCunney, ${ }^{3}$ Rolf Merget. ${ }^{1}$ Institute for Occupational Epidemiology and Risk Assessment (IERA) of Evonik Industries, Essen, Germany; ${ }^{2}$ Institute and Policlinic for Occupational Medicine, Environmental Medicine and Prevention Research, Köln, Germany; ${ }^{3}$ Institute for Prevention and Occupational Medicine of the German Social Accident Insurance, Bochum, Germany; ${ }^{4}$ AQura GmbH, Hanau, Germany; ${ }^{5}$ Wacker Chemie AG, Burghausen, Germany; ${ }^{6}$ Cabot Corporation,

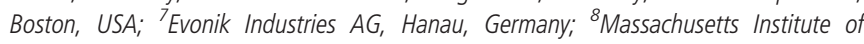
Technology (MIT), Boston, USA

10.1136/oemed-2014-102362.188

Objectives Synthetic amorphous silicas (SAS) are nanostructured polymorphs of silicon dioxide. We compared two different exposure assessments.

Method This study estimated cumulative exposure to inhalable SAS dust in 484 male workers from five German SAS producing plants. Two procedures (P1, P2) were applied. P1 was based on 